\title{
The effect of transverse steel rebars on the behavior of concrete beam reinforced with glass polymer rebars
}

\author{
Mojtaba Hosseini $^{a^{*}}$, Shahpoor Mehdipour ${ }^{b}$ and Peyman Beiranvand ${ }^{\mathrm{c}}$
}

\begin{abstract}
${ }^{a}$ Associate Professor, Department of Civil Engineering, Lorestan University, Khorramabad, Iran
${ }^{b}$ M.Sc, Department of Civil Engineering, Islamic Azad University Arak, Iran

${ }^{c}$ PhD Candidate, Department of Civil Engineering, Razi University, Kermanshah, Iran

\begin{tabular}{l}
\hline A R T I C L EI N F O \\
\hline Article history: \\
Received 6 November, 2016 \\
Accepted 14 July 2017 \\
Available online \\
14 July 2017 \\
\hline Keywords: \\
Glass fiber reinforced polymer \\
Finite element \\
Transverse rebars
\end{tabular}
\end{abstract}

\section{Introduction}

Experimental studies show that steel fibers can be used as stirrups in beams, frames, and decks and also can be used as strengthening shear reinforcement in precast beams with thin web. The reinforcing fibers can be added to concrete mixture in the critical regions of members created with pre-stressed concrete or in-cast concrete, in order to remove secondary reinforcements. Fiber-reinforced concretes can be used to improve ductility and the seismic strength of structures. High strength non-metallic fibers such as carbon, glass, and aramid, surrounded in a polymeric matrix, show a proper potential for concrete reinforcement. Polymeric resistant fibers are existing with different types such as rebar, mesh,

* Corresponding author.

E-mail addresses: Hosseini.m@lu.ac.ir (M. Hosseini) 
cable, ropes, tendons, laminate and a variety of structural profiles, which are usually known as FRP. In spite of the recent advances in this field, numerous researches are reported in many papers from different views of its structural application. FRPs have been used for structural reinforcing of structures. Hosseini et al. (2016) studied numerically some reinforced concrete beams containing bending and shear opening and strengthened with FRP sheet. They showed wrapping of the opening region with FRP sheets from the exterior zone was more effective than wrapping it from the inside of opening. Ramana et al. (2000) performed a study on the behavior of CFRP strengthened reinforced concrete beams with varying degrees of strengthening. They investigated the experimental results and analytical studies of flexural strengthening of RC beams by means of external attaching of high strength and light laminates of CFRP at the tensile region of the beam. In their study, the maximum increase in the first crack ultimate moments and stiffness of reinforced beams were found about 150 to 230 and $110 \%$, respectively. Islam et al. (2005) studied the shear strengthening of RC deep beams using external FRP reliable methods, in which 6 deep concrete beam were prepared for testing. The tests have shown that the use of FRP reliable method leads to decrease the propagation of critical diagonal cracks, and also leads to increase the load bearing capacity of the beam. Obaidat et al. (2011) studied the retrofitting of reinforced concrete beams using composite laminates. They reported the results of an experimental study regarding the structural behavior of completely damaged RC beams retrofitted with CFRP laminates in the shear or flexural regions. The use of CFRP laminates by external attaching method leads to increase the maximum load. The increase in maximum load of retrofitted specimens has been obtained about $23 \%$ and between 7 to $33 \%$ for shear and bending strengthening, respectively. Additionally, the strengthening has changed the failure mode to brittle failure. From the other side, the beam strengthening leads to decrease the cracks width compared with the control beam. Experimental results show that increase in the length of CFRP laminates in the flexural region leads to increase the repair efficiency and the concrete strength. In another research work Pannirselvam et al. (2008), modeled the strength of reinforced concrete beam with externally bonded FRP reinforcement. They evaluated the structural behavior of RC beams having external bond of FRP reinforcement in which three different steel ratios, two types of GFRP and two thicknesses in each GFRP were considered. According to their findings, the beams strengthened with GFRP laminates showed a better performance. Bending strength and ductility increases dramatically with the increase of the thickness of GFRP laminates. The increase of the loads of the initial crack for woven roving GFRP laminates with a thickness of $3 \mathrm{~mm}$ is more than $88.89 \%$, and for WRGFRP laminates with a thickness of $5 \mathrm{~mm}$ is about 56.01-64.69\%. The deformations due to the first cracks is very large in the tensile region of beams for the GFRP laminates and the maximum load reduction in the first crack for the $3 \mathrm{~mm}$-thick laminates is more than $50.59 \%$ and for 5 mm-thick laminates is more than $58.59 \%$. Jahangiri and Khaloo (2009) performed a study for investigating the behavior of reinforced concrete deep beams with web openings using finite element analysis. Their results have shown that the shear strength of beams will be decreased by increasing in the opening size. The amount of this reduction is equal to $15 \%$ for square openings and $20 \%$ for circular openings. By changing openings to circular, the ultimate strength of beams increases between 2 to $13 \%$, which the maximum increase is for beams having large openings in the internal shear span. Circular openings have a greater ductility about 2 to $16 \%$ than square openings. Park and Aboutaha (2009) worked on the strut-and-tie method (STM) for CFRP strengthened deep RC members. The STM method is used for analyzing RC deep beams strengthened with CFRP, when the CFRP acts as an extra tension. El Maaddawy and Sherif (2009) also performed a study about FRP composites for shear strengthening of reinforced concrete deep beams with openings. The paper presents the results of a research work on the assessment of the potential of the use of external CFRP laminates (surface) as a solution for strengthening to increase the strength of RC deep beams with openings. They showed that the increase in the strength due to using CFRP laminates is about 35 to 73 $\%$. While, regarding the test results, an analytical solution has been studied and examined for the prediction of the shear strength of RC deep beams with CFRP strengthened openings.

It has been revealed from the outcomes of the researches by Benmokrane et al. (1995) that glass fiber rebars are very light-weight and show elastic behavior until rupturing and also have a very high ultimate tensile strength, and a low ultimate strain and elastic modulus, at the same time. Its thermal expansion coefficient is similar to concrete. A beam reinforced with glass fiber rebars acts with 
satisfactory in compression like similar reinforced beams with metal rebars, however, in greater loads they break out more. The GFRP rebars used in this research have linear elastic behavior in compression and tension until the failure time. These rebars have a high strength to weight ratio, the ultimate strain and elastic modulus of them is small about $1.8 \%$ and $42 \mathrm{GPa}$, respectively. The results show that these rebars can be used in the building industry. Moreover, the mechanical and physical properties of these materials allow the use of these materials for designing of concrete structures such as beams, decks, columns, etc., which are reinforced with these composite rebars. From the other hand the use of these rebars is suitable for corrosive environments or beaches or areas with cycles of freezing and concretes containing salt, non-magnetic or insulating structures, military structures that are undetectable by radars, and underground structures. The initial cost of construction of these types of GFRP RC structures seems to be higher than conventional structures. The problem of corrosion in some structures becomes apparent only 5 years after their construction. After a few years, the cost of repair and maintenance if not be more than the initial cost, at least it is significant enough. This matter raises the chance for using this material in actual structures. A prospect of possible and different useable fibers in the building industry has been pointed out in a research by Parameswaran (1991). In the study worked by Cucchiara et al. (2003) the results of experimental tests performed on rectangular beams with simple supports and made of hook-like metallic-fiber concrete, with and without stirrup that are under vertical symmetrical 2-point load, are presented. Ashour (2006) performed a study on flexural and shear capacities of concrete beams reinforced with GFRP bars. In the present research work, flexural behavior of concrete beams reinforced with longitudinal rebars made of glass fiber reinforced polymer composites (GFRP), is investigated numerically using finite element method. For this purpose, a number of concrete beams with square sections are modeled in ABAQUS and the stress and deformation contours of different beams are compared.

\section{Mechanical properties of GFRP bars}

Based on ACI standard (2007) for beams reinforced with GFRP bars, the design tensile strength of polymeric rebars $\left(\mathrm{f}_{\mathrm{fu}}\right)$ will be obtained through the following equation:

$$
f_{f u}=C_{E} f_{f u}^{*}
$$

in which $\mathrm{C}_{\mathrm{E}}$ is the reduction coefficient related to environmental conditions depending on the fiber type and environmental conditions. $\mathrm{f}_{\mathrm{fu}}^{*}$ is the tensile strength provided by the manufacturer company of the FRP rebar, which is determined by tensile test.

\section{1 tensile strength}

FRP rebars in compression are weaker than tension. Compressive strength depends on the smooth or ribbed type of bars. The compressive strength of a type of GFRP is about 317 to $470 \mathrm{MPa}$, whereas, its tensile strength is between 552 to $896 \mathrm{MPa}$. An appropriate empirical relation is presented by ACI544 committee (related with fiber-reinforced concrete) to estimate the ultimate strength:

$$
S_{c}=A S\left(1-V_{c}\right)+B V_{r}(l / d) \text {, }
$$

where, $S$ is the ultimate stress of the matrix, $l / d$ is length to diameter ratio, $V$ is a volume of the fibers that is considered for considering accidental effect. $A$ and $B$ are constant numbers.

\subsection{The mechanical properties of stirrups}

The yielding stress of stirrups is equal to $340 \mathrm{MPa}$ and its ultimate is equal to $500 \mathrm{MPa}$ (A3 rebar). The Poisson's ratio and elastic modulus of the rebars are considered equal to 0.3 and $200 \mathrm{GPa}$, respectively. The strains corresponding to yielding and failure of rebars, are considered equal to 0.02 and 0.05 , respectively. The specific weight of steel is equal to $77 \mathrm{kN} / \mathrm{m}^{3}$.

\section{Modeling GFRP beams in ABAQUS}

\subsection{Concrete damage plasticity (CDP) constitutive model}

The failure criterion in the plastic range of material is expressed under compositional stresses. This criterion is divided into two major categories based on the material response to hydrostatic pressure. In 
most cases, ductile behavior is known by the name dependent on hydrostatic pressure and non-metallic materials such as soil, rock and concrete are of this category and are dependent to pressure. The following equation gives the isotropic scalar quantity of damage value:

$$
\sigma=(1-d) D_{o}^{e l}:\left(\varepsilon-\varepsilon^{p l}\right)=D^{e l}:\left(\varepsilon-\varepsilon^{p l}\right)
$$

where $d$ is the measurer of stiffness loss, Cauchy stress factor $(\sigma)$ is the initial (undamaged) elastic stiffness of materials, and similarly $\varepsilon$ is the strain tensor and $\mathrm{D}^{\mathrm{el}}$ is considered as the tensor of decreased elastic stiffness. The tensor of effective stress $\mathrm{D}^{\mathrm{el}}=(1-\mathrm{d}) \mathrm{D}_{\mathrm{o}}^{\mathrm{el}}$, is defined as follows:

$$
\bar{\sigma}=D^{e l}:\left(\varepsilon-\varepsilon^{p l}\right),
$$

where, $\varepsilon^{\mathrm{pl}}$ is plastic strain. It is required to consider the changes of loss value in the formulation.

$$
d=d\left(\bar{\sigma}, \tilde{\varepsilon}^{p l}\right) \text {. }
$$

The amount of stiffness loss is defined as loss variable $d_{c}$ in the compression zone, and variable $d_{t}$ in the tension zone. Therefore, the Cauchy stress tensor is dependent on the effective stress tensor, $\bar{\sigma}$ between the scalar loss parameter $(1-\mathrm{d})$ :

$$
\sigma=(1-d) \bar{\sigma}
$$

In the tension and compression states, the damage condition is divided into two stiffness parameters, separately, $\tilde{\varepsilon}_{t}^{p l}$ and $\tilde{\varepsilon}_{c}^{p l}$, which are the equivalent of plastic strain in tension and compression states. The development of hardening parameters was defined by the following equations:

$$
\tilde{\varepsilon}^{p l}=\left[\begin{array}{c}
\tilde{\varepsilon}_{c}^{p l} \\
\tilde{\varepsilon}_{t}^{p l}
\end{array}\right] \quad \text { and } \quad \tilde{\varepsilon}^{p l}=h\left(\bar{\sigma}, \tilde{\varepsilon}^{p l}\right) \cdot \dot{\varepsilon}^{p l}
$$

The cracking (in the tension) and crushing (in the compression) in the concrete varies by the increase in the stiffener (softeners) numbers. The yielding function specifies the distance of a surface in the stress state with the failure condition or damage rate:

$$
h\left(\bar{\sigma}, \tilde{\varepsilon}^{p l}\right) \leq 0 .
$$

Plastic flow is controlled by flow potential function $G(\bar{\sigma})$ based on the following equation:

$$
\dot{\varepsilon}^{p l}=\lambda \frac{\partial G(\bar{\sigma})}{\partial \bar{\sigma}}
$$

The plastic potential function, $G$, is also defined at the distance of effective stress. In order to study the deformation and strength of fiber reinforced concrete materials, four concrete types in the shape of beam were modeled in ABAQUS software. In each beam, four GFRP rebars with diameter of $12 \mathrm{~mm}$, and 10 steel rebars with diameter of $6 \mathrm{~mm}$ were placed vertically with a distance of $250 \mathrm{~mm}$, in order to prevent nucleation of shear cracks in the beams.

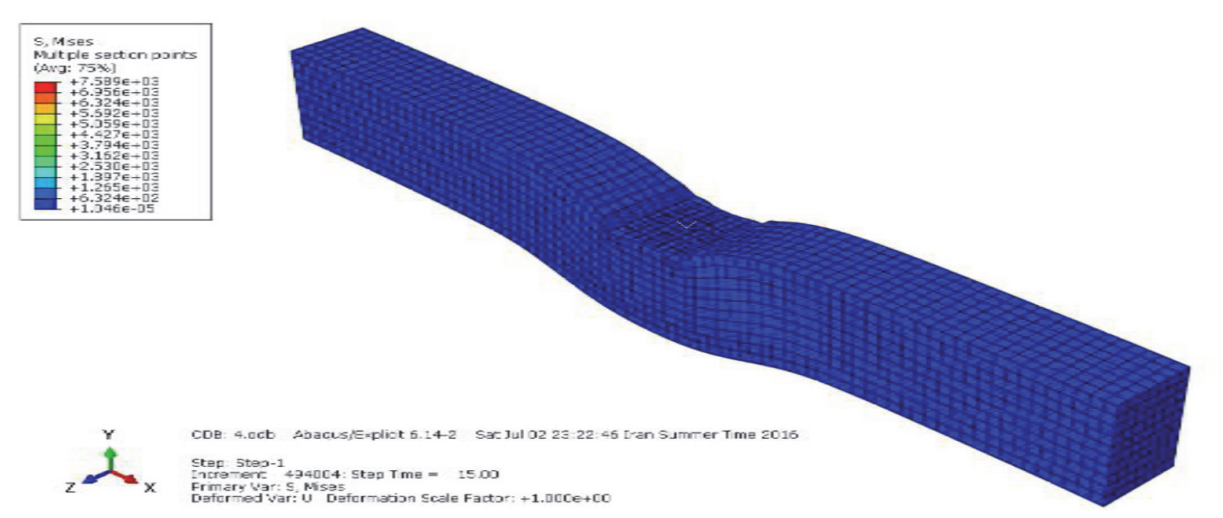

Fig. 1. Stress contour of beam no. 1 
The beam no. 1 was without transverse rebar, beam no. 2 had a row of transverse rebar, which was placed at the bottom and in the plane of vertical rebars. Beam no. 3 had a row of transverse rebars that was placed at the top and in the plane of vertical rebars; and the beam no. 4 had two rows of transverse rebars at the top and bottom of the beam in the plane of vertical rebars. The beams were gradually loaded under a load of 8 ton, and the amounts of displacement and strain at the middle of beams were compared together (Figs. 1 to 12). The elastic moduli of concrete and polymeric fibers were equal to 18.8 and $42 \mathrm{GPa}$, respectively, and the ultimate strain of polymeric fibers was equal to 0.18 . In addition, for modeling the mentioned concretes in ABAQUS, damaged concrete model was also considered.
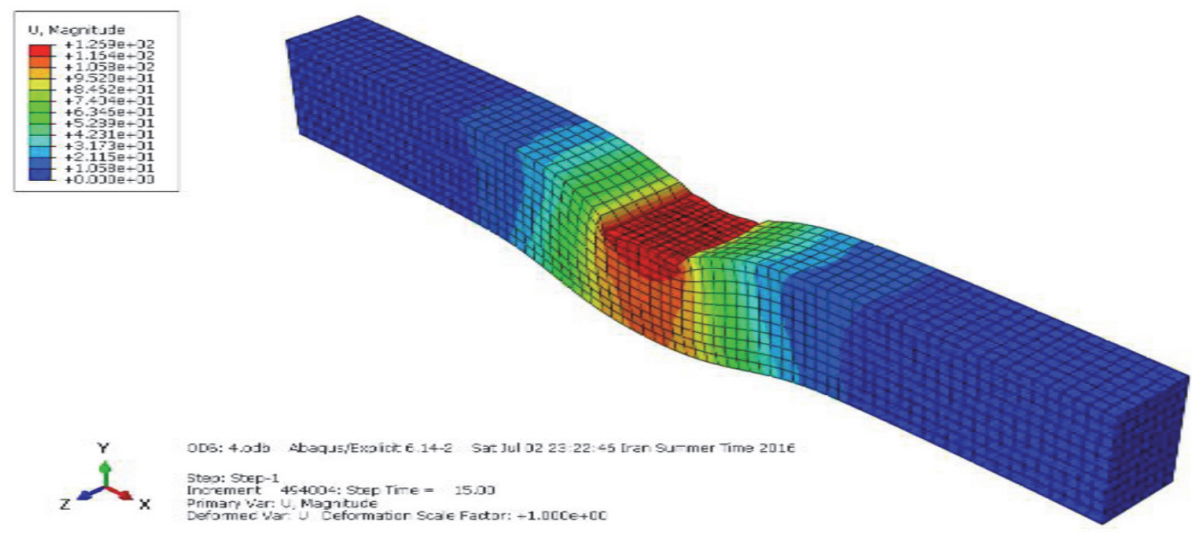

Fig. 2. Displacement contour of beam no. 1
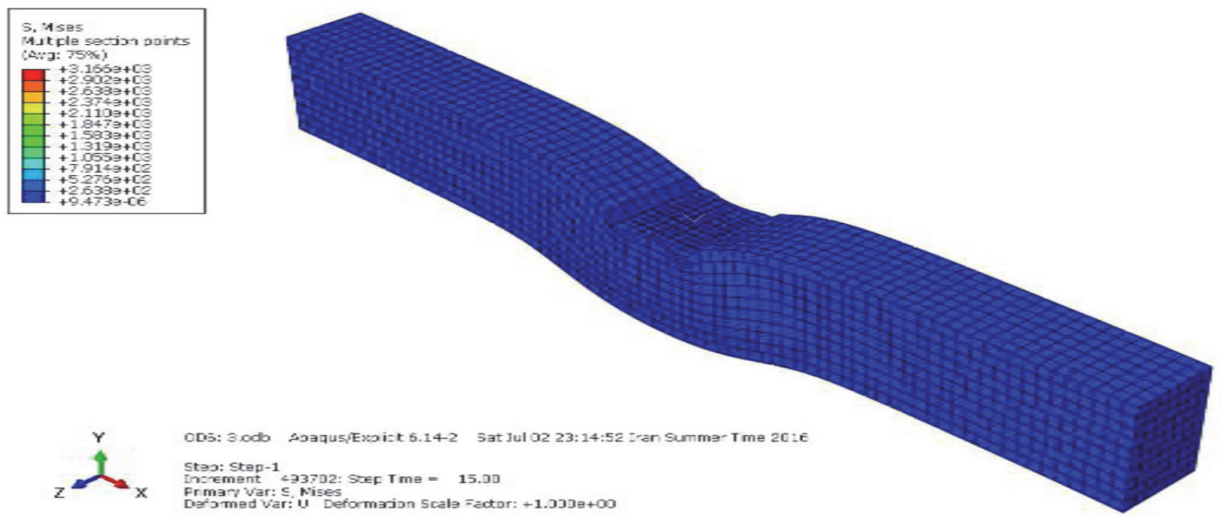

Fig. 3. Stress contour of beam no. 2

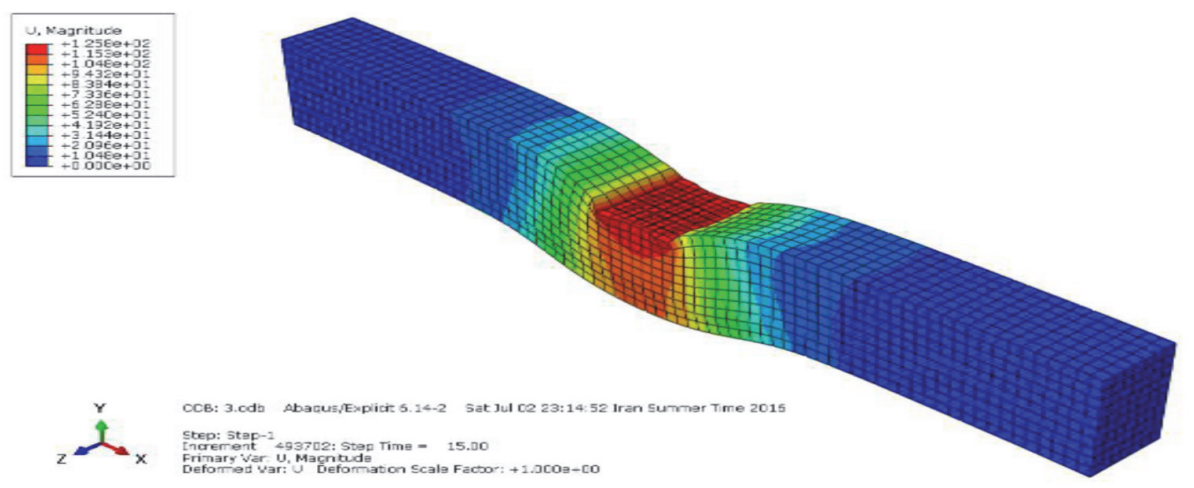

Fig. 4. Displacement contour of beam no. 2 

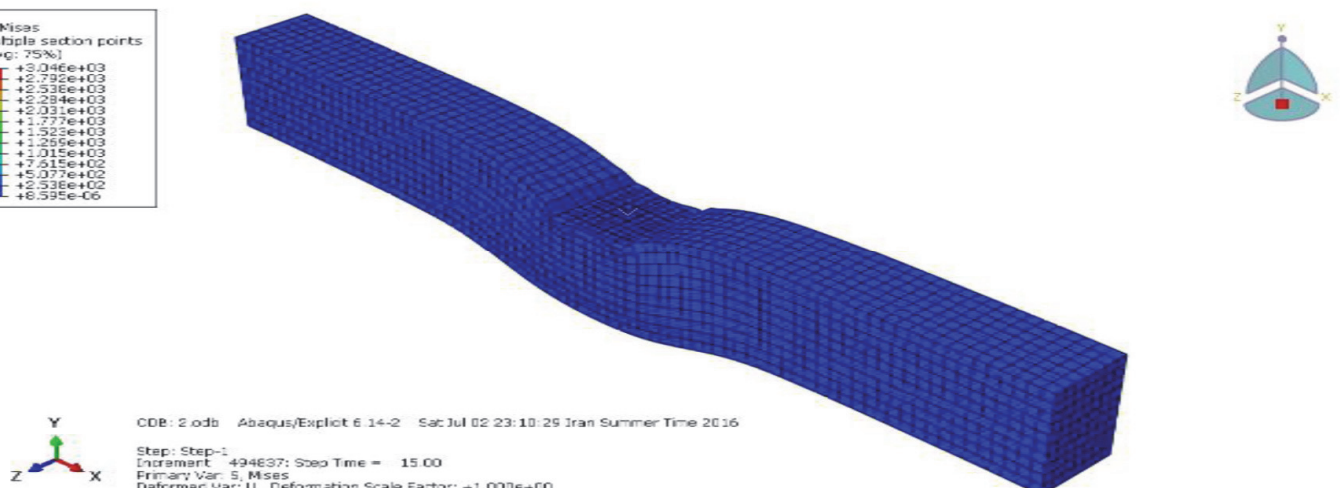

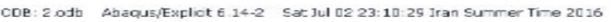
Step: Step-1
hurremert 494637 : S5e0 Tme -1500

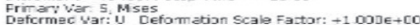

Fig. 5. Stress contour of beam no. 3

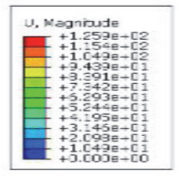

.2

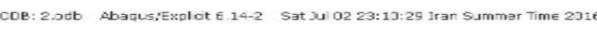

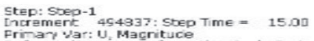

Fig. 6. Displacement contour of beam no. 3
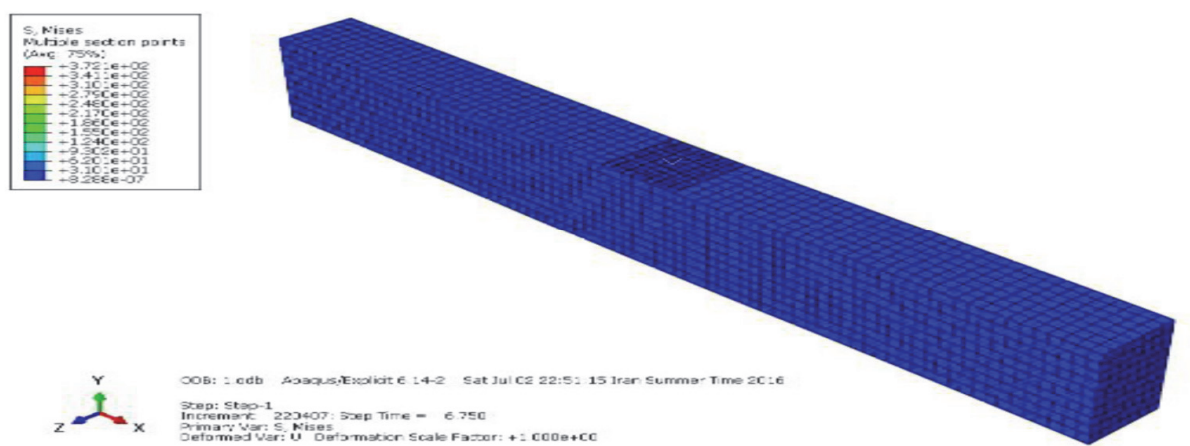

Fig. 7. Stress contour of beam no. 4

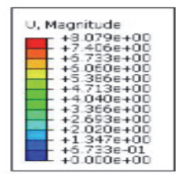

$\mathbf{L}$
$\mathrm{Z}$

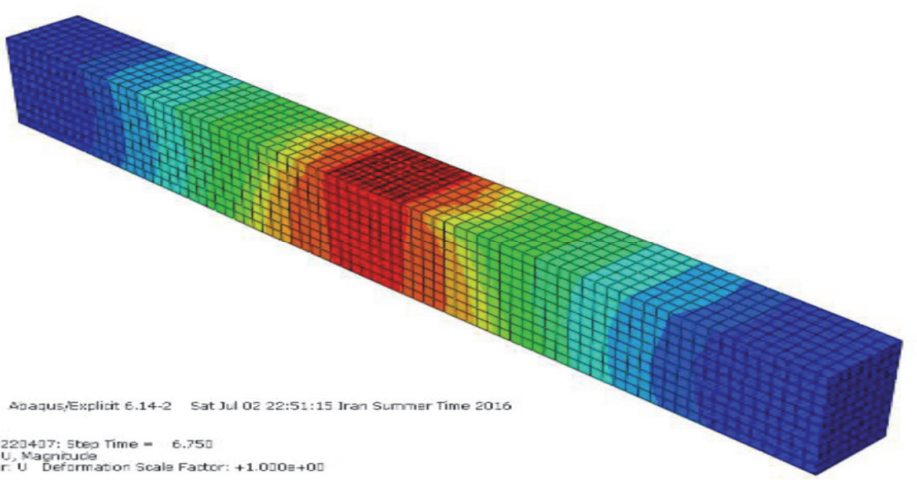

Fig. 8 Displacement contour of beam no. 4 


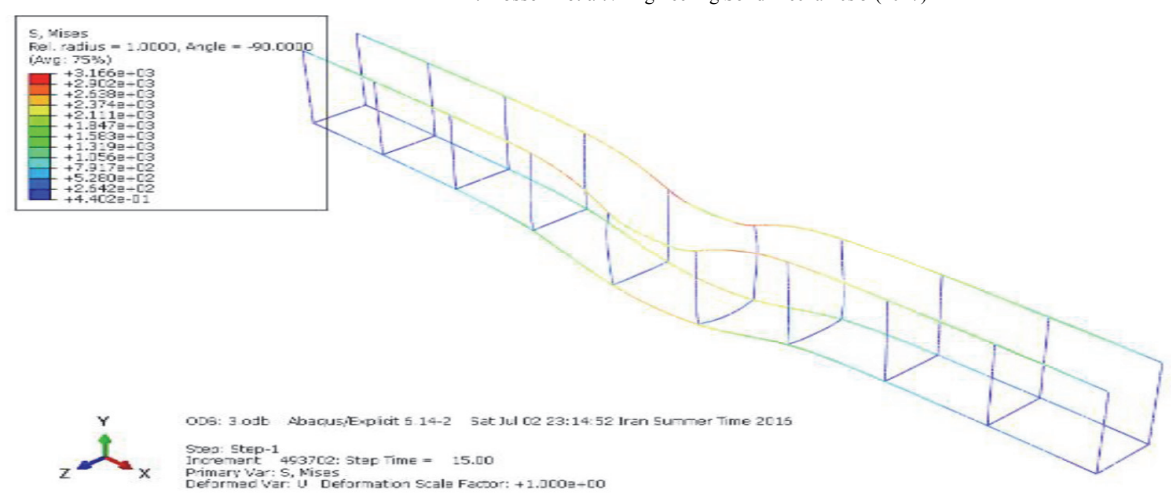

Fig. 9. Stress contour for reinforcement beam no. 1
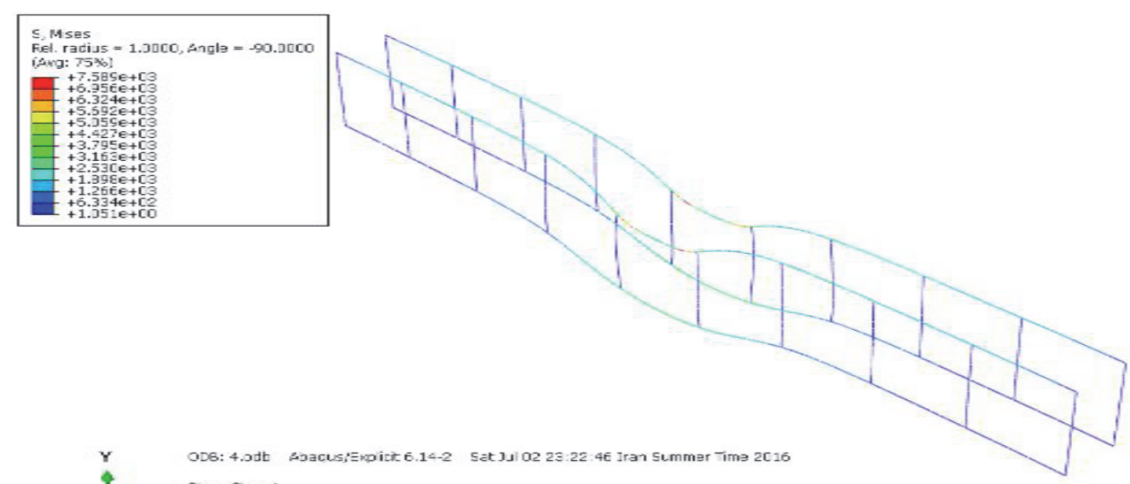

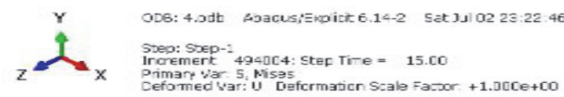

Fig. 10. Stress contour for reinforcement beam no. 2
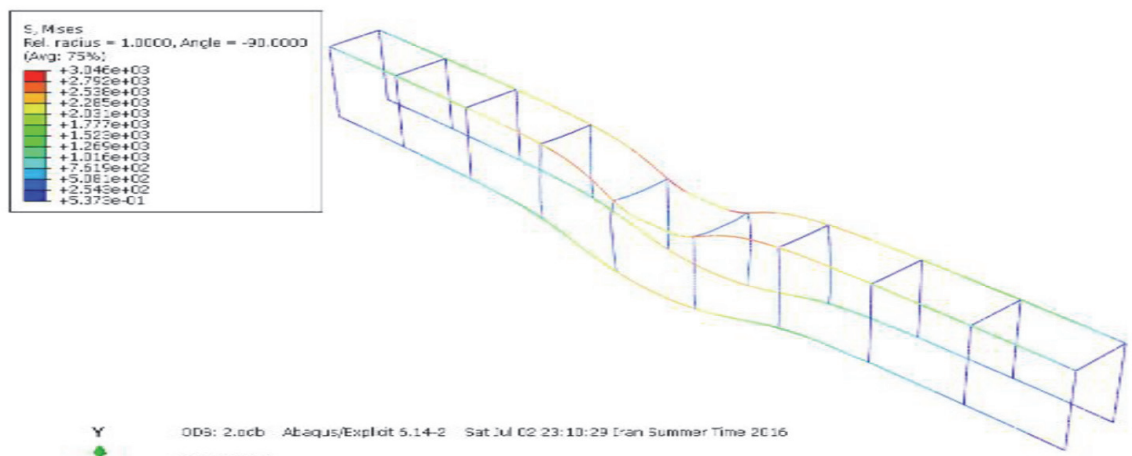

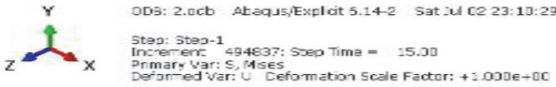

Fig. 11. Stress contour for reinforcement beam no. 3

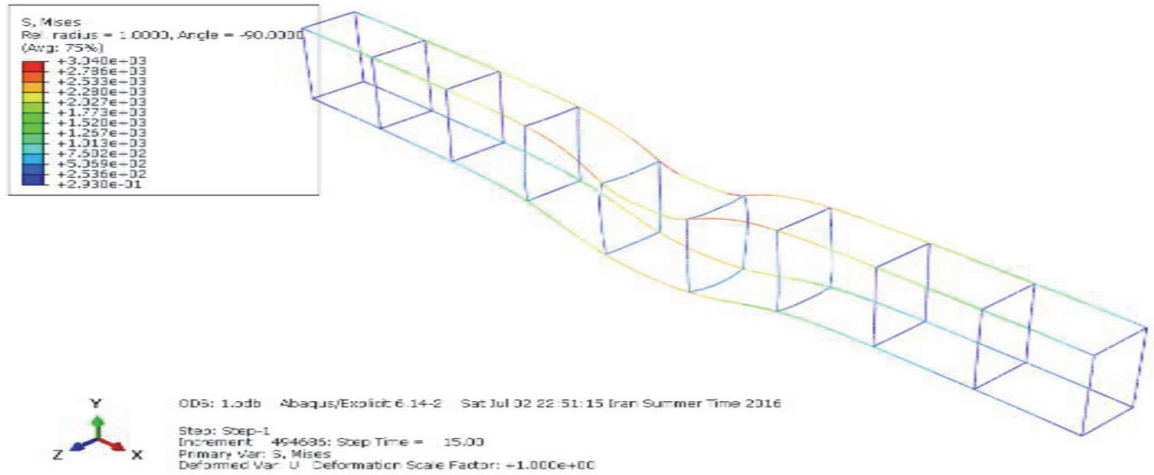

Fig. 12. Stress contour for reinforcement beam no. 4. 


\section{Discussion and Conclusion}

In all of the beams, at a constant load, the beams with more transverse rebar endured greater loads in comparison with the beams with less transverse rebar. At an identical load, the strain in the beam with less transverse rebar was more than the beams with more transverse rebars. After initial region that is corresponded to un-cracked section, for GFRP rebar reinforced beams, the load-displacement curve continues almost linearly until the ultimate load, which indicates that the GFRP did not yield until the failure moment. The beams reinforced with transverse GFRP rebars had the capability of larger ductility and energy dissipation. By increasing in the amount of the transverse rebars in the member, the failure of beams occurs in a higher ultimate load and also increasing in the amount of rebars had led to increase the area below load-displacement curve.

\section{References}

ACI Committee 440. (2007). Guide for the design and construction of structural concrete reinforced with FRP bars. American Concrete Institute.

Ashour, A. F. (2006). Flexural and shear capacities of concrete beams reinforced with GFRP bars. Construction and Building Materials, 20(10), 1005-1015.

Benmokrane, B., Chaallal, O., \& Masmoudi, R. (1995). Glass fibre reinforced plastic (GFRP) rebars for concrete structures. Construction and Building Materials, 9(6), 353-364.

Cucchiara, C., La Mendola, L., \& Papia, M. (2004). Effectiveness of stirrups and steel fibres as shear reinforcement. Cement and Concrete Composites, 26(7), 777-786.

El Maaddawy, T., \& Sherif, S. (2009). FRP composites for shear strengthening of reinforced concrete deep beams with openings. Composite Structures, 89(1), 60-69.

Hosseini, M., Amiri, A., \& Beiranvand, P. (2016). Numerical analysis of reinforced concrete beams containing bending and shear opening and strengthened with FRP sheet. Engineering Solid Mechanics, 4(3), 145-152.

Islam, M. R., Mansur, M. A., \& Maalej, M. (2005). Shear strengthening of RC deep beams using externally bonded FRP systems. Cement and Concrete Composites, 27(3), 413-420.

Jahangiri V. \& Khaloo A., (2009) .investigating the behavior of reinforced concrete deep beams with web openings using finite element analysis, Sharif University, Iran.

Obaidat, Y. T., Heyden, S., Dahlblom, O., Abu-Farsakh, G., \& Abdel-Jawad, Y. (2011). Retrofitting of reinforced concrete beams using composite laminates. Construction and Building Materials, 25(2), 591-597.

Pannirselvam, N., Raghunath, P. N., \& Suguna, K. (2008). Strength Modeling of Reinforced Concrete Beam with Externally Bonded Fibre Reinforcement Polymer Reinforcement. American Journal of Engineering and Applied Sciences, 1(3).

Park, S., \& Aboutaha, R. S. (2009). Strut-and-tie method for CFRP strengthened deep RC members. Journal of Structural Engineering, 135(6), 632-643.

Parameswaran, V. S. (1991). Fibre-reinforced concrete: a versatile construction material. Building and Environment, 26(3), 301-305.

Ramana, V. P. V., Kant, T. A. R. U. N., Morton, S. E., Dutta, P. K., Mukherjee, A. B. H. I. J. I. T., \& Desai, Y. M. (2000). Behavior of CFRPC strengthened reinforced concrete beams with varying degrees of strengthening. Composites Part B: Engineering, 31(6), 461-470.

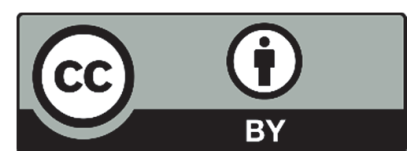

(C) 2017 by the authors; licensee Growing Science, Canada. This is an open access article distributed under the terms and conditions of the Creative Commons Attribution (CC-BY) license (http://creativecommons.org/licenses/by/4.0/). 